\title{
http://dx.doi.org/10.12795/PH.2012.v26.i02.08
}

\section{RESEÑAS DE LIBROS}

Piedad Bolaños Donoso y Jesús Cañas Murillo, Introducción o Loa para la apertura del teatro en Sevilla, de Juan Pablo Forner, estudio y edición crítica, Secretariado de Publicaciones de la Universidad de Sevilla, 2010, 333 pp. ISBN: 9788447212743.

Piedad Bolaños Donoso y Jesús Cañas Murillo, ambos catedráticos de Literatura Española de las Universidades de Sevilla y Extremadura respectivamente, ofrecen al lector un estudio sobre un autor concreto, Juan Pablo Forner, y un momento específico de la historia del teatro sevillano del siglo XVIII: su reapertura en 1795 . En trescientas treinta y tres páginas se ocupan, con profusión, de una pequeña obra de este gran autor dieciochesco, la Introducción o Loa que se recitó para la apertura del teatro en Sevilla, la cual desencadenó la redacción de un conjunto de escritos polémicos, algunos de los cuales eran hasta el momento desconocidos y aparecen ahora rescatados, y por vez primera dados a la estampa, en el libro del que nos estamos ocupando, publicado por el Secretariado de Publicaciones de la Universidad de Sevilla.

Hasta la publicación del trabajo de Bolaños y Cañas, la crítica se había centrado en estudios particulares sobre algunos escritos de Forner o sobre su implicación en la vida cultural de la época, pero más allá de Sevilla y el teatro en el siglo XVIII, de Francisco Aguilar Piñal, carecíamos de un trabajo unitario en el que apoyarnos para tratar sobre el teatro hispalense del setecientos. El estudio que reseñamos cubre una laguna importante al respecto: el cierre y apertura del teatro en Sevilla a finales del XVIII.

La obra que nos presentan los dos investigadores mencionados consta de diferentes partes. Se abre con un extenso capítulo introductorio en el que los autores incluyen cinco apartados: el primero con los datos biográficos sobre Juan Pablo Forner y su interrelación con las polémicas y el mundo cultural e intelectual de la época, el segundo a propósito del ambiente teatral en la Sevilla de los últimos años del siglo XVIII, el tercero con el estudio estructural y compositivo de la Introducción o Loa, el cuarto con el análisis de las respuestas al texto antedicho y, por último, el que trata un texto relacionado con la polémica y que describimos más adelante: los Desengaños útiles y avisos importantes al literato no sevillano escrita por su amigo el gaditano. Tras este prefacio de análisis, el trabajo 
de Bolaños y Cañas incluye otras secciones: las dedicadas a los criterios de edición y a la bibliografía, la que recoge cinco textos de la polémica y, finalmente, una de apéndices, en la que transcriben cuatro interesantes documentos relacionados con el tema del libro. Pasemos, a continuación, a tratar sobre cada uno de los apartados en particular.

Comienza este estudio, como se ha indicado, con un capítulo introductorio, donde en primer lugar, bajo el epígrafe "Forner polemista", se ofrece un repaso por la vida y obra de este personaje. En él Bolaños y Cañas prestan especial atención a su ingente y variada producción escrita: literaria, científica y erudita. Destacan la faceta de polemista del emeritense, que se vio inmerso en disputas dialécticas de diverso calado, entre las que se incluye la controversia teatral, consecuencia de la difusión de la Introducción o Loa, que los dos investigadores editan y analizan.

Tras presentarnos, pues, a Juan Pablo Forner, los autores se dedican a describir, siguiendo un orden cronológico, los hitos fundamentales que perfilaron el ambiente teatral en la Sevilla del último tercio del setecientos, cuando pueden apreciarse los antecedentes que permiten contextualizar la Introducción o Loa. Así, con la lectura de este apartado, titulado "Ambiente teatral sevillano a finales del Siglo XVIII", aprendemos cómo algunas autoridades prohibían la actuación de los cómicos mientras otras eran de opinión más favorable y consideraban "el teatro como un medio a través del cual se podría educar a todos los españoles" (p. 28). Con Olavide la capital hispalense gozó de un renacimiento cultural, especialmente en lo relativo al teatro, planificándose, incluso, la construcción de un nuevo coliseo. Sin embargo, poco después volvieron las supresiones y represiones de todo lo que oliera a cómico. Los dos autores del volumen que reseñamos ponen en práctica un método de análisis sobresaliente, pues son numerosísimos los textos de la época con los que acompañan y corroboran sus afirmaciones, como cartas, informes y dictámenes de distintas instancias gubernamentales, unos a favor y otros en contra del teatro y de su licitud. Con estos antecedentes llegan los autores al año de 1795, cuando el 17 de octubre, día de su estreno, "Calderi presentó una variada y amena función" (p. 41) donde se recitó la Introducción o Loa compuesta por Forner para esa ocasión. Lamentablemente, la polémica que desató el texto del emeritense, además de otros factores analizados en la obra, derivó en una nueva prohibición del teatro en Sevilla, esta vez en 1800. Culmina, así, la descripción del contexto en el que surgió la pieza de Forner y sus consecuencias. Destacamos su excepcional aportación al conocimiento de la sociología del teatro sevillano en el siglo XVIII.

En el siguiente epígrafe de la "Introducción" de esta obra, titulado por sus autores "La Introducción o Loa [... para la apertura del teatro en Sevilla y sus escritos contrarios", se trata de este texto, que "aborda el polémico tema de la moralidad del teatro, de su licitud, como se dijo en buena parte de la historia" (p. 49), de lo que conocemos otros ejemplos, como algunos escritos de Blas Nasarre, Nicolás Fernández de Moratín o Gaspar Melchor de Jovellanos. Analizan los editores 
la composición de la Introducción o Loa de Forner, teniendo en cuenta el texto mismo, incluida la Carta que sirve de prólogo, escrita por un literato no sevillano, a un amigo suyo de Cádiz, que la precede y que justifica, en buena medida, el contenido y las pretensiones de la Introducción o Loa. Las razones que esgrime la Carta son estudiadas por Bolaños y Cañas y puestas en relación con el contenido mismo de la pieza de Forner. Se analiza, por otro lado, la estructura de la obra, que contiene una "presentación de la compañía" que va a actuar, un "debate sobre el teatro" (con una evolución en el pensamiento del personaje del Bachiller, pasando de reprobar la comedia a alabarla), un "enlace con la comedia" que seguirá a la Introducción o Loa y una "alabanza de Sevilla" como ciudad que recuperará su "antiguo esplendor" tras la reapertura del teatro (p. 51). Por último, los dos autores cierran este apartado con unas referencias a la recepción de la citada obra de Forner, afirmando que fue especialmente conocida en el ambiente para el que se escribió, y en el que enseguida suscitó la polémica. Además, hacen saber que hasta sus ediciones actuales, entre las que se encuentra la que contiene este libro, únicamente se editó en 1796, el año siguiente a su estreno, y no se conserva ningún testimonio manuscrito.

"Dos nuevas contestaciones, manuscritas, a Forner" es el título del cuarto apartado de la "Introducción". A pesar de su brevedad, los investigadores analizan, citando los textos, las principales críticas que se vertieron contra Forner y su Introducción o Loa en el ambiente de recepción al que nos referíamos con anterioridad, y lo hacen siguiendo la Anti-loa para la cerradura del teatro de Sevilla, compuesta por un anónimo autor que se oculta tras las iniciales “D.J.P.F.F.D.C.D.L.A.R.” (Bolaños y Cañas infieren que quizás se trate de don Juan Perote, que ya había escrito contra Forner, pero dejan claro que no tienen seguridad al respecto), y las Notas marginales a la Carta Proemial, y a la Loa escrita por el $S^{\text {or }} D^{\text {on }}$ Juan Pablo.

Culmina el capítulo introductorio, que concentra el estudio crítico sobre la Introducción o Loa de Forner y su contexto, con un apartado destinado a la noticia de que en el volumen se incluye "Un texto impreso poco conocido: Desengaños útiles y avisos importantes al literato no sevillano. Contextacion y respuesta à la consulta que hizo sobre la Loa, que se recitó en la apertura del Teatro en Sevilla año de 1795, escrita por su amigo el gaditano".

Tras este primer capítulo los autores incluyen otras secciones más técnicas: "Nuestra edición" y "Bibliografía Selecta", donde exponen los criterios que siguen para editar los textos y describen el ejemplar de la Introducción o Loa de Forner utilizado: el conservado en la Biblioteca IX Marqués de la Encomienda, de Almendralejo (Badajoz). Por otro lado, relacionan la bibliografía utilizada y la clasifican en ediciones y estudios (generales y biográficos, escritos de Forner y polémicas del emeritense).

El cuarto bloque lo constituyen "Los textos de la polémica", donde Bolaños y Cañas editan paleográficamente cinco escritos relacionados con las disputas 
sobre la apertura y cierre del teatro en la capital del Guadalquivir. Hemos de mencionar muy especialmente en estas líneas que los investigadores han realizado una verdadera labor de recuperación de documentos. Los textos que se editan son la Introducción o Loa [... para la apertura del teatro en Sevilla, de Juan Pablo Forner, la Anti-Loa para la cerradura del teatro en Sevilla, las Notas marginales a la Carta Proemial y a la Loa escrita por el $S^{r} D^{n}$ Juan Pablo, los Desengaños útiles y avisos importantes al literato no sevillano escrita por su amigo el gaditano y una selección de las reacciones de Forner según don Emilio Cotarelo y Mori y la documentación por él publicada en la Bibliografía de las controversias sobre la licitud del teatro en España.

Sin lugar a dudas, la Carta y los 538 versos que conforman la Introducción o Loa de Forner son los que merecen, a juicio de los autores, un mayor y más erudito estudio, que se manifiesta en la profundidad y profusión de sus notas a pie de página, 135 anotaciones que contienen aclaraciones léxicas, bibliográficas, sociales, históricas, literarias y eruditas, en un exhaustivo análisis crítico-filológico y socio-literario que pone de manifiesto la plausibilidad de la obra que describimos tanto en su generalidad como en sus especificidades y pequeños detalles, como puede comprobarse en la inclusión de retratos (sobre todo de Forner) y en la reproducción de las portadas o primeras páginas de todos los textos editados en el volumen, incluyendo el de la Introducción o Loa del ejemplar que ha servido como texto base. No obstante lo anterior, Bolaños y Cañas no descuidan el estudio de los otros cuatro textos, pues conciben los restantes escritos de la polémica como complementarios y destacables por su riqueza, especialmente relacionados con la misma obra del emeritense y con el ambiente teatral en la ciudad de Sevilla. Un total de 400 notas dan fe de estas afirmaciones.

Concluye la obra con unos "Apéndices" donde se transcriben, siguiendo los mismos criterios que para los textos anteriores, cuatro manuscritos de la época que, más allá de las obras implicadas directamente en la polémica sobre la apertura del teatro en Sevilla, complementan el ambiente sociocultural y normativo en el que se desarrolló. Son la Carta de Pablo de Olavide sobre la construcción del Teatro de Medina Sidonia; un documento de 1769 que otorga Facultad al Duque de Medinasidonia para dar a censo dos habitaciones, tres cocheras y un solar, pertenecientes a los Mayorazgos que posee en la forma aqui expresada; el Informe del Revisor de las piezas que se habian de representar en el teatro en 1777 (redactado y firmado dos años más tarde) y el Recibo de arrendamiento. $D^{n}$ Lazaro Calderi del estado de Arenales [1794-1795].

En definitiva, la Introducción o Loa para la apertura del teatro en Sevilla, de Juan Pablo Forner, estudiada y editada por los catedráticos Piedad Bolaños y Jesús Cañas, contribuye al estudio filológico y sociológico del teatro de diferentes maneras y desde distintas perspectivas, entre la que destacamos fundamentalmente la labor de reconstrucción, recuperación y publicación de un patrimonio documental tan desconocido como básico. Aparecen en un único volumen, por 
primera vez, todos los textos de los que se tiene noticia sobre la mencionada disputa teatral hispalense, los cuales se sitúan en la órbita del texto de Forner que da nombre al libro. La edición de estos testimonios coadyuba, indudablemente, a un mejor conocimiento sobre el autor emeritense y las polémicas teatrales. El análisis textual y sociológico exhaustivo y erudito, la anotación profusa, la destacable labor de documentación y la agradable lectura son los cuatro pilares que permitirán el éxito de esta obra, de imprescindible consulta para el lector especialista, avezado o curioso, del teatro dieciochesco en la capital del Guadalquivir.

Ismael López Martín

ismael@unex.es

Universidad de Extremadura

Lirola Delgado, Pilar, Al-Mu'tamid y los Abadies. El esplendor del reino de Sevilla (s. XI), Almería: Fundación Ibn Tufayl de Estudios Árabes, 2011, 356 pp. ISBN: 9788493675110.

Este nuevo libro de Pilar Lirola, Profesora Titular del Área de Estudios Árabes e Islámicos en la Facultad de Filosofía y Letras de la Universidad de Cádiz, está dedicado al rey poeta de Sevilla Al-Mu'tamid y, de manera paralela, a su familia, los Abadíes, así como a algunas figuras que influyeron directamente en su vida política, artística o familiar, como fueron su esposa Rumaykìy, llamada también I'timād, y su amigo Ibn 'Ammār.

Anteriormente, la profesora Lirola ya había dedicado algún tiempo a investigar sobre algunos de estos personajes ilustres, cuyas biografías han sido publicadas en la Biblioteca de al-Andalus.

Posiblemente, nos encontramos ante la obra más completa que se ha realizado hasta el momento sobre al-Mu'tamid, para la cual se han consultado fuentes árabes de todo tipo, entre las que se encuentran fuentes históricas, literarias, jurídicas, botánicas y agrícolas. Esta diversidad de obras, algunas coetáneas y otras posteriores, nos confirman que el rey sevillano formó parte de una familia ilustre por su repercusión política y social, pero también por su influencia cultural y artística, hasta el punto de inspirar algunas manifestaciones musicales, pictóricas o poéticas aún hoy en día.

La profesora Lirola no sólo aglutina en un solo libro todas las informaciones contenidas en las fuentes árabes y los estudios más significativos realizados sobre el tema, sino que pretende en este proceso revisar lo dicho hasta el momento, poniendo en relación dichas fuentes y estudios para contrastarlos y rectificar todo lo contradictorio, confuso, incongruente, erróneo e inverosímil que hay en ellos. De este modo, descubre algunas imprecisiones en fechas, hechos, nombres, posiciones y cargos contenidos en las mismas obras árabes, "ya 
que podrían haber sido tergiversados al paso de los tiempos" (p. 25), al mismo tiempo que critica las consideraciones de algunos estudiosos contemporáneos, quienes por incomprensión o por intención tachan a al-Mu'tamid, entre otras cosas, de "hombre que no atendía a sus obligaciones, entregado únicamente a la vida refinada, al lujo y a la diversión” (p. 19). El hecho mismo de esta revisión lleva a la autora a aleccionar al lector para que sea capaz de diferenciar los estudios basados en fuentes de los estudios no académicos y meramente divulgativos y "no dar por cierta la primera noticia que encontremos, como con relativa frecuencia hacen historiadores aficionados introduciendo confusión en el discurso" (p.24). Hay que tener en cuenta que la historia de al-Mu'tamid, como decíamos, ha sido contada desde el mismo s. XI hasta la actualidad, ya que ha sido "capaz de ganarse incluso después de muerto una simpatía y un cariño como ningún otro personaje de la historia de al-Andalus" (p. 237). Pero, a la par, esta popularidad y cercanía hacen que se difundan noticias no demasiado ciertas sobre su vida personal, artística o política.

Por tanto, gracias a este análisis tan detallado y pormenorizado que realiza Pilar Lirola, el lector tiene la impresión de hallarse frente a una obra seria y rigurosa. Pero, a la fidelidad que manifiesta la autora como filóloga, se le une, además, su capacidad literaria, ya que está escrita en un lenguaje sencillo, lo que hace que su lectura sea muy amena y apta para todo aquél que esté interesado en la historia de al-Andalus, independientemente de que sea arabista o no. Además, a esta sencillez de redacción se suma el acierto de ir intercalando textos originales, en su mayoría poesías escritas por al-Mu'tamid, Rumaykīya, Ibn 'Ammār y otros poetas de su tiempo o posteriores, que la misma autora ha traducido o, en su caso, también revisado, lo que ayuda a comprender o a contextualizar aquello que se nos explica, al tiempo que nos deleita por la belleza y sensibilidad de dichas composiciones literarias.

En cuanto a la estructura de la obra, además de unas observaciones preliminares (pp. 11-12) sobre el modo de trascripción empleado y algunas consideraciones referentes a la bibliografía citada, la autora comparte su autoría con algunos de sus colaboradores, como son: E. Navarro y Ortíz, por la realización del índice; V. C. Navarro Oltra, por la elaboración de los mapas y J. M. Puerta Vílchez y Nairuz Bakur, por la confección de la portada. Seguidamente, en la introducción (pp. 13-22) nos presenta el contexto en el que se desarrolla la vida de los Abadíes, que no es más ni menos que el s. XI en al-Andalus, considerada como la época de máximo esplendor político y cultural y, al mismo tiempo, la edad de oro de la literatura andalusí. En este espacio, la autora explica de forma resumida lo que representaba la familia Abadí en Sevilla, que llegó a ser, gracias a ella, el más grande de los reinos de Taifas, para luego centrarse en sus dos principales miembros: al-Mu'tamid y su padre al-Mu'tadid. En este espacio de su obra, Lirola hace un llamamiento al rigor científico, rehusando cualquier estudio que no respete y, en cambio, menosprecie el legado que nos dejaron los 
andalusíes en sus más de siete siglos de presencia en nuestra Península, utilizando este trabajo "como homenaje a esta incomparable etapa histórica que desde diferentes medios e ideologías han vendido y venden como una amenaza, dando muestra de incultura y de manipulación interesada" (p. 22). Considero, por tanto, que en esta obra que aquí reseñamos hay dos lecturas: la primera de todas, la más evidente, es la revisión que se realiza de las fuentes y estudios en relación a al-Mu'tamid y a su círculo más íntimo (ya sea el familiar, artístico o político) y la puesta al día de los resultados. Y una segunda lectura, menos evidente, que es la confirmación de que sólo en las fuentes se puede encontrar la información verídica. Realizar este ejercicio le da potestad a la autora para rechazar las interpretaciones, refundiciones y consideraciones de algunos estudiosos que no basan sus trabajos en fuentes originales.

Siguiendo con la estructura de la obra, y tras la introducción, se dedican unas páginas (pp. 23-32) a comentar las fuentes y los estudios que se han realizado sobre los Abadíes y que han servido de base en este trabajo, entre las que se hallan las obras de Ibn Ḥazm, Ibn Ḥayyān, al-'Uḍrī, al-Ḥumaydī, Ibn Labbāna, Ibn Bassām e Ibn Jāqān, contemporáneos a al-Mu'tadid y a al-Mu'tamid, y las obras del cadí 'Iyāọ, 'Abd al-Wāḥid, al-Marrākušī, Ibn al-Jațīb, Ibn Jaldūn y de alMaqqarī, entre otros, posteriores a ellos. A este apartado le siguen unas breves páginas (pp. 33-35) en que se da noticia sobre los orígenes de la familia abadí, las cuales sirven de preámbulo para los siguientes capítulos (pp. 37-252), en los que se aborda la vida de cuatro ilustres Abadíes: el cadí Ismā̄îl Ibn 'Abbād, el cadí Abū 1-Qāsim Muḥammad Ibn 'Abbād, al-Mu'taḍid y al-Mu'tamid, siendo, respectivamente, el bisabuelo, abuelo y padre del rey sevillano, así como la de Rumaykīya, su esposa y compañera hasta su muerte (pp. 253-272). Los descendientes de ésta y de otras mujeres con las que al-Mu'tamid compartió su vida también tienen cabida en este estudio (pp. 273-306). Para finalizar, la profesora Lirola dedica un apartado a las recreaciones artísticas que se han inspirado en la figura de al-Mu'tamid (pp. 307-311).

Este trabajo culmina con la presentación de una bibliografía extensísima y puesta al día, así como de un índice de mapas, cuadros e ilustraciones, los cuales se intercalan oportunamente a lo largo de toda la obra, para finalizar con un índice onomástico y toponímico muy riguroso.

En definitiva, la obra de Pilar Lirola, Al-Mu'tamid y los Abadies. El esplendor del reino de Sevilla (s. XI), es un magnífico trabajo de investigación, que tiene como resultado un fiel recorrido por la historia de los Abadíes sevillanos y, en especial, por la vida y la obra del rey poeta al-Mu'tamid, por la de su esposa preferida Rumaykìya y por la de su amigo el poeta y también dirigente Ibn 'Ammār. El proceso de revisión que realiza ante nuestros ojos causa en el lector una sensación de encontrarse, por fin, ante la verdad de los acontecimientos, unos hechos que, hasta ahora, se nos han presentado confusos por la cantidad de interpretaciones, traducciones y consideraciones hechas al respecto. Es una 
cuidadosa edición para una obra imprescindible, dedicada a todo aquél que esté interesado en la vida y la obra de al-Mu'tamid y en este periodo tan significativo de la historia de al-Andalus.

Inmaculada Camarero Castellano

inmacamarero@telefonica.net

Universidad de Sevilla

\section{Vinagre Lobo, Miguel Ángel, Los libros griegos de interpretación de los sueños, Zaragoza: Pórtico, 2011, 357 pp. ISBN: 9788479560850.}

El profesor Vinagre Lobo ha publicado otros trabajos sobre aspectos puntuales de los tratados de interpretación de los sueños, sobre la dimensión literaria del sueño o sobre la terminología del soñar. Frente a ellos, este libro se presenta como un estudio de conjunto, que pretende analizar y clasificar todos los tratamientos del sueño y el soñar dispersos. La tarea es ardua y de ello dará cuenta la mera enumeración de los capítulos del libro en que, después de una somera introducción, se articula la materia. La introducción presenta ya su sistema de clasificación que contiene precisiones resaltables respecto al sistema de del Corno (D. Del Corno, "Ricerche sull' onirocritica greca", Rendiconti dell' Istituto Lombardo 96, 1962, 334-366) que diferenciaba en oniromántica / onirología englobando en el primer apartado a los tratados interpretativos frente a los tratados que atienden a la dimensión médica o filosófica que serían onirológicos. Está de acuerdo en la división pero, en coherencia con los datos del léxico griego, prefiere llamar a los primeros onirocríticos y a los segundos onirológicos. Su clasificación de los tratados se basa en la finalidad de los mismos y así distingue tratados onirocríticos, obras de compilación erudita, literatura incubatoria, tratados onirológicos médicos, tratados onirológicos filosóficos y obras que no encajan bien en ningún grupo, como las de Filón, Elio Arístides y Sinesio. Tal clasificación se percibe parcialmente incluso en la estructura de los capítulos: el capítulo I trata de los orígenes, de los tratados de los siglos V y IV a.C. El capítulo II estudia los tratados de Aristóteles y los peripatéticos. El capítulo III analiza la aportación estoica. El capítulo IV explica el tratamiento del sueño en época imperial, que gira en torno a Filón de Alejandría. El capítulo V considera la aportación de Galeno y los precedentes médicos. El capítulo VI estudia los discursos sagrados de Elio Arístides, una especie de diario onírico individual, que aportan un punto de vista propio. El capítulo VII trata de la figura señera de Artemidoro de Daldis autor del único tratado onirocrítico conservado y del problema de sus fuentes. Es el más largo — casi cien páginas- lo que se justifica por su carácter único. Un capítulo final, de recapitulación sólo de nombre, analiza la diacronía de las teorías, presenta importantes comparaciones 
entre autores y añade datos de autores posteriores al daldiano. Se nos ofrece una bibliografía muy completa, diferenciando autores antiguos y modernos.

$\mathrm{El}$ autor ha organizado la materia de estudio, que en sí es dispersa y de límites imprecisos, de una manera coherente y clara. El capítulo I nos introduce en los remotos orígenes de la preocupación por el sueño, en los primeros testimonios ya literarios, tan tempranos en lengua griega como Il.1.62, y en las dimensiones distintas del soñar que rozan con el ámbito de la adivinación, de la metodología clínica, del afán religioso o del negocio heredado (33-34). Y así hasta llegar al tratado onirocrítico más antiguo, el de Antifonte de Atenas.

Para cada autor transmitido suficientemente el estudio se organiza siguiendo un mismo patrón: la finalidad del tratado, su estructura, clasificación de los sueños que ofrece y problemas especiales que plantea el tratado. Ese es el caso de las obras de Hipócrates, Aristóteles, Filón, Galeno, Elio Arístides y Artemidoro. Pero hay también cabida para resaltar la especificidad de cada aproximación al sueño y para considerar de manera detallada cada problema, cada interrogante abierta. En todos los apartados nos ofrece una visión muy completa del estado de cada cuestión con referencias bibliográficas abundantísimas. No hay espacio para comentar todas pero sí para recoger algunas de las aportaciones: la fuente del tratado del seudo Hipócrates pudo ser Paniasis de Halicarnaso (58 y 222ss) al que se le atribuye una posición preeminente en el establecimiento de las clasificaciones de sueños (p.314); no se puede identificar al Antípatro mencionado por Cicerón con el mencionado por Artemidoro; Herófilo debe considerarse en la tradición médica en la que introduce como novedad los sueños mixtos y atiende a las causas del sueño. Se insiste en que no es un tratado onirocrítico el De somnis de Filón y en que su clasificación procede de la de Posidonio y es tripartita. Y, sobre todo, se producen aportaciones relevantes en el análisis de las fuentes de Artemidoro y de las clasificaciones de los sueños. Entre ellas sostiene la idea de que sólo haya una base empírica en el tratado y defiende la dependencia del tratado de fuentes literarias, entre otras cosas porque le resultaba necesario para ennoblecer su profesión de adivino itinerante (208). En el análisis de las fuentes utiliza un método ya probado previamente (M.A. Vinagre, "Artemidoro Daldiano ante la tradición onirocrítica previa", Excerpta Philologica II, 1992,113-130) para indicar el tratado atribuido a Femónoe como fuente, o para reducir la importancia de Antifonte como fuente, para determinar la dependencia respecto a Paniasis en la clasificación del sueño predictivo en cinco tipos. En otras ocasiones, por ejemplo, en el caso de Aristandro, adivino de Alejandro, recoge testimonios dispersos para presentar un esbozo suficiente de su actividad y proporcionar contexto para las ocasiones en que Artemidoro lo usa como fuente, mencionado expresamente al menos en una ocasión un tratado suyo (236 y ss.) con lo que sería "el fundador de la onirocrítica como técnica" (240). Con sólo dos menciones al tratado de Aristandro, la del Daldiano y otra de Seudo Luciano, la prudencia le hace mencionar la alternativa de una 
edición de los sueños realizada posteriormente. Se precisan aspectos de detalle, como la patria de Dionisio y se analiza minuciosamente la cuestión de la personalidad del anónimo criticado en IV 22 como uno más de los autores de literatura incubatoria vinculada a Serapis (276-285).

El capítulo de recapitulaciones ofrece una muy necesaria perspectiva después de tan minuciosa exposición y permite percibir, por una parte, las diferencias entre las aproximaciones onirológicas y, por otra, los puntos de contacto de las clasificaciones onirocríticas. Y añade datos de la persistencia de ambas en autores no vinculados al género: de Posidonio procedería la clasificación, tripartita y onirológica, de Tertuliano y Yámblico, y de una fuente común a Artemidoro, la de Macrobio, pentepartita y onirocrítica. Hace también una apuesta arriesgada al defender que la clasificación en tres elementos, onirológica y estoica, procede de la de cinco.

Con la organización elegida muchos autores, onirocríticos casi todos, son considerados sólo como fuentes de algún otro, de Artemidoro en particular, en cuyas menciones han pervivido o se nos han transmitido: Aristandro, Apolonio Febo, etc. La otra opción posible estrictamente cronológica habría tenido el inconveniente de duplicar las referencias y los tratamientos. Se produce también un fenómeno interesante: algunos autores, como Cicerón, terminan recibiendo un tratamiento extenso, indirecto pero tan completo como el de los autores griegos directamente considerados.

Un último mérito debe ser notado: los textos griegos están recogidos en el $G R O S R^{3}$ y, como el mismo autor señala, en muchos casos la suya es la primera traducción al español con lo que ello supone de dificultad añadida, especialmente en textos técnicos. Se ha optado por no presentar los textos griegos, cosa que habría multiplicado la extensión del libro y sólo aparecen entre paréntesis los términos clave.

En resumen, una obra imprescindible para quien intente tener una visión global de los tratados sobre sueños y particularmente fructífera para el lector más técnicamente interesado en la investigación de las fuentes de las teorías, clasificaciones y conceptos presentes en los tratados sobre sueños.

Rafael Martínez Vázquez

rmartinez@us.es

Universidad de Sevilla 
Saad, Mohamed Saad (coord.), Interculturalidad, Lengua y Traducción. Estudios aplicados al español y al árabe, Madrid: Instituto Egipcio de Estudios Islámicos de Madrid, 2009. 258 pp. + ilustraciones. ISBN: 9788469239056.

A pesar de tratarse de campos con la mayor proyección profesional, aún no son muchos los estudios que aborden de un modo conjunto campos tales como la interculturalidad, la lengua y la traducción árabe-español. Precisamente por ello debemos dar la bienvenida a esta obra que se nos presenta, coordinada por el Profesor Saad Mohamed de la Universidad Pablo de Olavide de Sevilla.

La obra, presentada bajo una sencilla pero cuidada edición del Instituto Egipcio de Estudios Islámicos, tiene una estructura miscelánea, dividida en diferentes bloques temáticos. Tras un prólogo del coordinador de la obra, Saad Mohamed Saad, en el que se describe la estructura y contenidos de la obra, y una introducción, en la que Mahmoud El Sayed Aly aborda brevemente diversas reflexiones sobre la traducción de la poesía, comienza el primero de estos bloques, dedicado precisamente a analizar diversos aspectos contrastivos entre el español y el árabe. En este ámbito es de agradecer la presencia de una contribución como la que nos presenta la Dra. Abeer Mohamed Abd El Salam, en la que nos revela muchos aspectos de esa gran inquietud que comparten aquellos que se dedican al estudio y a la enseñanza de la lengua árabe ¿Cómo se materializa el proceso inverso? Es decir, ¿Cómo se sumerge un arabófono en el entorno lingüístico y cultural español? Asimismo, este bloque queda bien reforzado con una contribución del coordinador de esta obra en la que se presentan una serie de aspectos contrastivos entre los demostrativos en árabe y en español, en la que se aportan herramientas concretas para los estudiosos de la lingüística comparada.

El segundo de los bloques temáticos de la obra se centra en un aspecto tan complejo como apasionante, como es el de la traducción del texto literario. Este bloque comienza con una brillante contribución de la Profesora Rosa Martínez Lillo, en la que a partir de un ejercicio práctico, como es la traducción de un texto del poeta Adonis, nos sumerge en una experiencia "doblemente maravillosa y sugestiva" en la que se permite "saborear la palabra", en palabras de la autora. Efectivamente, la lectura de los textos de Adonis traducidos por esta autora permite entender la traducción no sólo como un trabajo técnico sino como un fruto de la inspiración artística. Finalmente, este bloque se cierra con una nueva contribución del coordinador de la obra, en la que se analizan diversos aspectos técnicos que deben de ser valorados por el traductor literario a la hora de enfrentarse a un texto en lengua árabe. Un capítulo de marcado carácter técnico, bien estructurado y explicado a base de ejemplos y que resulta de indudable interés.

Por último, el tercer bloque de la obra tiene un marcado carácter histórico. Esta compuesto por dos contribuciones en la que los autores, la Profesora María Crego, el Profesor Ahmed Shafik se centran, respectivamente, en el análisis 
de la terminología empleada en textos históricos y filosóficos. Se trata de dos contribuciones que presentan notable interés si tenemos en cuenta que en ambos trabajos los autores parten de fuentes medievales en las que resulta bastante más complejo especificar el sentido de los términos sin un conocimiento previo del entorno histórico y cultural en el que se plasmaron dichas fuentes.

Es evidente que se trata de un amplio elenco de materias las que son analizadas en los diferentes capítulos de esta obra. Quizá por ello, sopesándola en su conjunto cabría preguntarnos si tales capítulos responden a un proyecto unitario de trabajo colectivo o bien se trata de una mera compilación circunstancial de trabajos que apenas comparten el uso de las lenguas española y árabe como herramientas de trabajo. Es cierto que la amplitud del elenco de materias abordadas, tales como la literatura, la historia o la lingüística hace difícil dotar de un sentido unitario a esta obra. Sin embargo, la calidad de las contribuciones incluidas en este libro, a nuestro entender, permiten que obviemos tales consideraciones. En este sentido, es evidente que estamos ante una obra que, por los motivos antes citados, presenta un claro interés, tanto por la utilidad de las materias abordadas en sus contribuciones como por la calidad mostrada en su tratamiento por los autores. Su lectura es amena y ágil y permite crear nuevas inquietudes al lector interesado en la lengua y en la cultura árabes.

Juan Manuel Uruburu Colsa

uruburu@us.es

Universidad de Sevilla 